\title{
Intraperitoneal Injection of cinnamon extract (Cinnamomum zeylanicum) on Passive Avoidance Learning in Rats with Streptozotocin-induced Alzheimer's Disease
}

\section{Ramesh Ahmadi*, Masoomeh Toloeghamary, Saeede Pishghadam}

Department of Physiology, Qom Branch, Islamic Azad University, Qom, Iran

Study Area: Qom, Iran

Coordinates: $34^{\circ} 38^{\prime} 24^{\prime \prime} \mathrm{N}$; $50^{\circ} 52^{\prime} 35^{\prime \prime} \mathrm{E}$

Key words: Dimethyl sulfoxide, DMSO, Streptozotocin, STZ

\section{Abstract}

Alzheimer's disease is one of the most prevalent brain neurodegenerative diseases, in which neurons are destroyed specially in the areas related to cognitive activities. In the past, many drug therapies have been introduced for Alzheimer's disease that despite significant developments, they were not succeeded completely. In the present research, the effects of extract of cinnamon (Cinnamomum zeylanicum) were studied on consolidation phase of memory in Streptozotocin male wistar rats model of Alzheimer's disease. Total 30 male wistar rats were divided into five groups. One group kept intact, given no injection whereas groups were treated with dimethyl sulfoxide (DMSO), dimethyl sulfoxide and Streptozotocin, Streptozotocin (STZ) as intracerebral ventricular and cinnamon extract through intraperitoneal. To assess learning and memory in rats, the passive avoidance learning test was performed. Intracerebroventicular Streptozotocin injection caused severe injuries to learning capacity and memory of rats, whereas the group received $C$. zeylanicum extract was found to improve such impairments.

\section{Introduction:}

Various neurodegenerative diseases may cause progressive memory and cognitive performance impairments. Alzheimer's disease is a progressive irremediable brain disorder with an unclear etiology having no treatment. Its symptoms include losing memory, confusion, improper diagnosis, a disorder in recognizing direction, and losing language skills (Frydman-Marom, 2011). In the sporadic type of this disease together with cognitive disorders, progressively a severe injury occurs in the metabolism of Glucose and brain's energy (Lannert \& Hoyer, 1999). Glucose is an effective factor in learning and memory (Hoyer \& Lannert, 2008). Any damage to Glucose metabolism leads to an intensification of brain dementia (Kumar et al., 1991). Meanwhile, clinical researchers demonstrated a relation between Alzheimer's disease and resistance to Insulin in the brain (Gasparini et al., 2002). Laboratory studies show that Streptozotocin injection through intracerebroventricular affect on learning and memory of rats and also on metabolic processes in the brain of these animals similar to the effects of sporadic type of Alzheimer's disease (Ishrat et al., 2006). Reduction of neurons in a number of areas significant for learning and memory, particularly Hippocampus is one of the notable factors in it (Herring et al., 2008). With the progress of our knowledge about heterogeneity regarding this disease, the necessity for finding effective compounds with fewer side effects in preventing Alzheimer or treatment or the problems resulting from it felt strongly. It seems that alternative treatments, particularly herbal medicines, inaugurated a new way in the treatment of Alzheimer's disease (Bush, 2001). Hence, various herbal medicines have been applied to intensify memory and treat amnesia, out of which cinnamon can be recalled. Treatment with cinnamon is common among people for years. Cinnamon extract has an anti-pain effect (Lee et al., 2002), anti-clotting effect on blood (Anderson et al., 2004), activity against free radicals (Duke et al., 2008), and adjusting blood sugar (Roussel et al., 2009). On the basis of the mentioned beneficial effects of cinnamon extract, the researchers are detecting a proper and reliable medicine to treat Alzheimer's disease, the present study reviewed effects of cinnamon extract on learning and memory in rats by injecting Streptozotocin to intracerebral ventricular through behavior.

*Corresponding Author:ramahmd@yahoo.com 
Materials and methods:

Cinnamomum hydro-alcoholic extract was obtained by an extractor. In this research, 30 male wistar rats were used having an approximate weight range between 230-250 $\mathrm{g}$ in standard laboratory condition with proper water and food in natural day-night conditions within a temperature range of $23 \pm 2$ degree centigrade. The 30 rats were further divided into 5 groups having 6 rats each. In each group, consolidation stage was reviewed and tested among passive avoidance learning stages.

In the classified groups, the following issues were considered:

- An intact group with no injection.

-Control group a: with dimethyl sulfoxide injection in intraperitoneal

- Control group b: having surgery and injection to CSF on 1st and 3rd days after surgery and dimethyl sulfoxide injection in intraperitoneal on 7 th day after surgery

-A group with Alzheimer model including surgery and injection to CSF together with STZ $(1.5 \mathrm{mg} / \mathrm{kg})$ on 1st and 3 rd days after surgery and DMSO injection to intraperitoneal on 7 th day after surgery for 4 days

-Experimental group includes surgery and injection inside CSF together with STZ on 1st and 3rd days after surgery and injection of cinnamon to intraperitoneal with $125 \mathrm{mg} / \mathrm{kg}$ on 7 th day after surgery for 4 days.

All the groups were tested on the 5 th day.

For surgery and cannulation, first of all rats were weighed and anesthetized by injecting the drug to intraperitoneal, then their heads were fixed in stereotaxic system, and a longitudinal cut was made behind the head which revealed the skull. After specifying Steriotox following the Anderson et al. (2003) and Pilot studies, lateral cerebral ventricular was recognized, and injecting cannula was entered to the right ventricle. Streptozotocin injection (with dosage of $1.5 \mathrm{mg} / \mathrm{kg}$ ) in the groups suffering from Alzheimer's disease was applied using Hamilton syringe in the place. The solution prepared for the Alzheimer's disease was injected intravenously in the 1st and 2ns days after surgery. The injections were given with minimum stress to the animal.

To evaluate the authenticity of the operation and accuracy of the location of injection and surgery, from the pattern, the same volume of one percent blue methylene, opening the skull, taking out the brain and fixing it in 10\% formalin solution and evaluation and investigation of the distribution of color in right ventricular were applied. One week after injecting Streptozotocin intracerebral ventricular, rats were undergone passive avoidance learning by Shuttle Box. Delay time in entering to dark part was registered. Training stage was continued for 4 days. The testing stage was fulfilled 24 hours after training stage, which the rats were tested on the 5th day in this protocol. The spent time to enter the dark room after opening the door was considered as delay time and in the both stages of learning and memory evaluation up to 300 seconds. A longer delay to enter the dark room in memory evaluation stage was considered as the symbol of better learning. The synthetic cerebrospinal fluid material purchased from Merckelmann Company was made from these materials: $\mathrm{NaCl}_{125}, \mathrm{Mgcl}_{2}$ 1.3, $\mathrm{CaCl}_{2} 2.5, \mathrm{KH}_{2} \mathrm{PO}_{4}$, $\mathrm{NaHCO}_{3} 26$, Cloucose 10 . At the end of the experiments, all the animals were anaesthetized with ether, and then 2 $\mathrm{ml}$ of diluted methylene blue color was injected through the cannula into the right lateral ventricle, and then, by opening the skull, completely removed the brain and placed in a formaldehyde solution. For one week in $10 \%$ to obtain the needed hardness for cutting. In the next step, the thin sections were taken and the slices were viewed by loop from the sample. Compared the colour locations and the accuracy of the location of the cannula with the corresponding diagram mentioned in the Paxinos \& Watson Atlas. If the injection site of each animal was not found to be correct, we removed the results for that animal.

Statistical analysis: In this study, data was analyzed by one-way variance analysis and Tukey Test.

\section{Results :}

Result suggests that STZ intracerebral ventricular injection led to severe impairment of rats' learning and memory, and there is a significant difference among Alzheimer group and an experimental group who received the extract. Results of intraperitoneal injection of cinnamon extract (Cinnamomum zeylanicum) with dosage of $125 \mathrm{mg} / \mathrm{kg}$ for 4 consecutive days on passive avoidance learning in Alzheimer Model after training concerning amount of primary delay in entrance to dark room (Step Through Latency $\{\mathrm{STL}\}$ ) and duration of the spent time (Total time in Dark Compartment $\{$ TDC $\}$ ) and duration of spent time in light room (Total time in Light Compartment $\{$ TLC $\}$ ) wereas follows:

a. Effect of cinnamon on Step Through Latency to dark section of Shuttle Box on Test Day: the obtained results show that there is a significant difference on level of $95 \%$ reliability among at least one pair of various groups $(\mathrm{p}<0.02, \mathrm{~F}=3.53, \mathrm{df}=4.25)$. The Tukey subsequent test is presented in Table-1 to compare the groups two-by-two.

Table 1: Results of Tukey subsequent test (Step Through Latency to dark section)

\begin{tabular}{lccc}
\hline Group & Sample size & SubtypesforAlfa= 0.05 \\
& & 1 & 2 \\
\hline - Alzheimer Model: & 6 & 12.8 \\
$\quad$ DMSO+csf+stz & & & \\
- Control a: DMSO & 6 & 46.1 \\
- Control b: DMSO+csf & 6 & 46.6 \\
- Exp. group: extract+stz & 6 & 60.5 \\
- Intact & 6 & 63.5 \\
- Significance level & & 0.781 \\
\hline
\end{tabular}


Based on two-by-two comparison, there is just a difference among stz + csf + DMSO (Alzheimer Model) and all studying groups.

b. Effect of Cinnamon on the time in dark compartment (TDC) in Shuttle Box in the test day: the results of one-way variance analysis demonstrated that there is a meaningful difference between at least one pair of various groups $(\mathrm{df}=4.25, \mathrm{~F}=4.252, \mathrm{sig}=0.009)$. To compare groups two-by-two, Tukey subsequent test shall be used. The results of such comparison are presented in Table 2.

$\frac{\text { Table 1: Results of Tukey Subsequent Test }}{\text { (total time in dark compartment) }}$

\section{Group} Sample size SubtypesforAlfa $=0.05$

-Control a: DMSO
-Control b: DMSO+csf
-Intact
-Experiment group:
extract+stz
-Alzheimer Model:
DMSO+csf+stz

12

Significance leve

Two-by-two comparison based on Tukey Test demonstrates that there is just a difference among group stz + csf + DMSO (Alzheimer model) and all studying groups. Comparing pairs of other groups, there is a significant statistical difference regarding total time in dark compartment.

c. Effect of Cinnamon extract on total time in light compartment (TLC) in Shuttle Box in test day: the results of variance analysis, comparing total time in light compartment, demonstrated that there is a significant difference among at least two groups of studying groups $(\mathrm{F}=4.473, \mathrm{df}=4.25, \mathrm{sig}=0.007)$. Table 3 shows two-by-two comparison of averages.

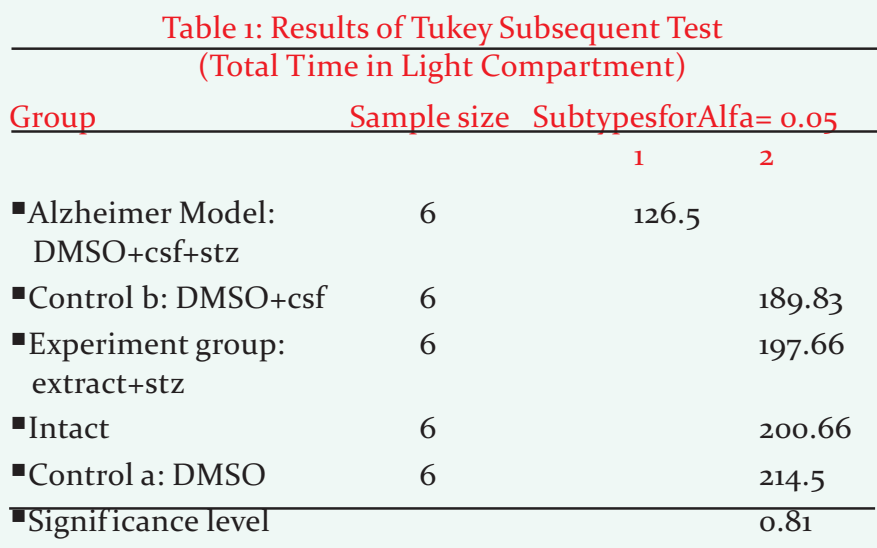

Results demonstrates there is a significant difference for the variable of Time in Light Compartment, among group stz + csf + DMSO (Alzheimer model) and all studying groups, and other groups are placed in one categoryin Tukey classification,

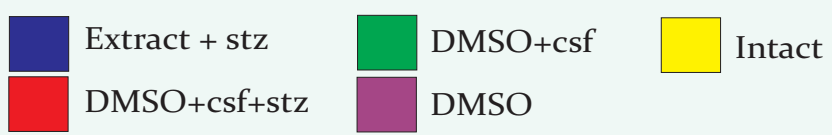

Bars with "astrix" do not differ statistically from each other at $5 \%$ level

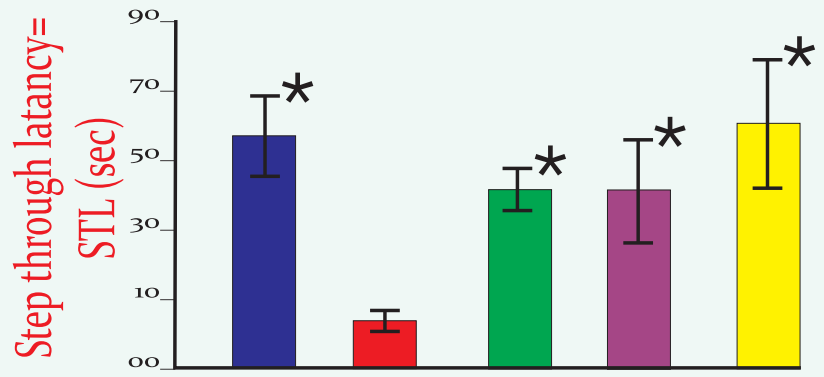

Figure-1: Results of reviewing Cinnamon extract intraperitoneal (with dosage of $125 \mathrm{mg} / \mathrm{kg}$ ) after 4 consecutive days during step through latency (STL) to dark compartment in male rats suffering from Alzheimer's disease in proportionate to control groups.

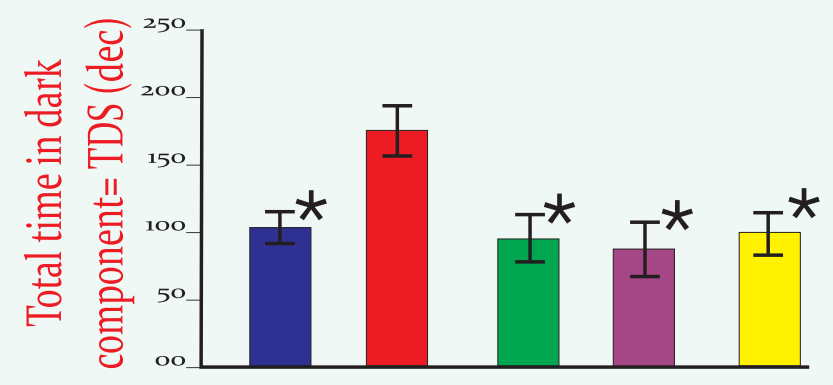

Figure-2: Results of reviewing Cinnamon extract intraperitoneal (with dosage of $125 \mathrm{mg} / \mathrm{kg}$ ) after 4 days of training on step through latency (STL) to dark compartment (TDC) based on seconds in male rats suffering from Alzheimer's disease in proportionate to control groups

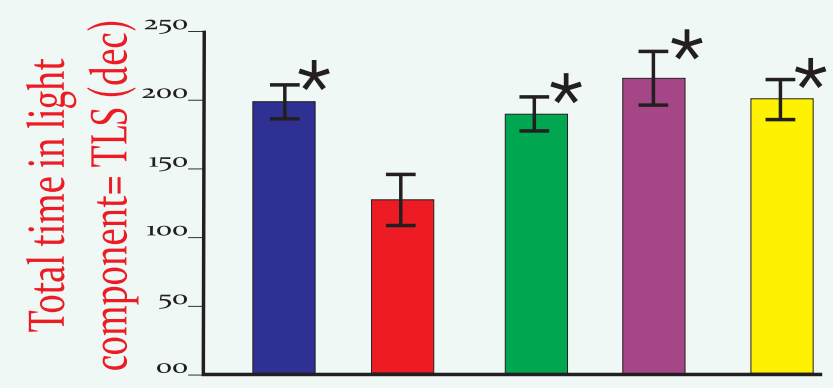

Figure-3: Results of reviewing Cinnamon extract intraperitoneal (with dosage of $125 \mathrm{mg} / \mathrm{kg}$ ) after 4 consecutive days on step through latency (STL) to light compartment (TLC) in male rats suffering from Alzheimer's disease in proportionate to controlgroups.

\section{Discussion:}

Alzheimer's disease is a progressive neuro-degenerative disease (Hoyer et al., 200o) and cellular structure of neurons are destroyed which affect memory and behavior (Adsersen et al., 2006). In a study by Ishrat et al. (2009), it 
was revealed that injection of STZ intracerebral ventricular led to a severe disorder of learning and memory. Furthermore, it was also demonstrated by them that neurotransmitter-steel choline seems to be necessary for its formation, memory growth, and retrieval, where its synthesis requires glucose analysis and the existence of insulin to control the activity of steel choline transferors. STZ intracerebral ventricular with decrease in energy metabolism and oxidative stress by controlling ATP synthesis and Steel coenzyme A and as the result, synthesis of steel choline may lead to damage to cognitive performances that finally activity of enzyme of steel choline transferaz is decreased in hippocampus of rats with Alzheimer's disease due to STZ (Lannert \& Hoyer, 1998). Results gained from passive avoidance learning tests in this study showed that STZ injection caused severe learning and memory damage in rats.

One of the important factors which have a positive effect on memory consolidation stage is to stimulate muscarinic receptors of a Cholinergic system. Many reactions made in parts of the sympathetic system are intervened by muscarinic receptors (Wallenstein, 1991). Based on studies performed by Siegel et al. (2006), a neurological transmitter in the system is Cholinergic steel choline that affects through Nicotinic and muscarinic receptors. Our result revealed the intraperitoneal cinnamon injection (Cinnamomum zeylanicum) with dosage of $125 \mathrm{mg} / \mathrm{kg}$ for 4 consecutive days concerning primary step through latency to dark compartment and step through latency to light compartment in Shuttle Box device comparing with Alzheimer's group demonstrated that the extract receptor group enters with more delay to dark compartment, and also they stayed a long time in light compartment that this issue demonstrated suitable effect of cinnamon extract in memory improvement which is due to Triploid compounds of the extract including Limonon and Linalol, Transcinam-Aldehid (Sciegel et al., 2006) and Phenol compounds such as Eugenol as well as anticholine specification of cinnamon extract that this specification is due to the existence of compounds such as Glycosides of Monoterpene and Terpenes included in the extract. cinnamaldehyde has some Choline which assists brain to develop steel choline which is a chemical material used in neurological cells (Vangalapati et al., 2012). Probably, Triploid compounds in Cinnamon extract may also stimulate Muscarinic receptors of cholinergic system and have a positive effect on memory consolidation stage and treatment of Alzheimer's disease. The brain uses $20 \%$ of oxygen in the body and since ROS (Reaction oxygen species) is produced, cells are exposed to oxidative stress (Assunção et al., 2011) and this factor cause reduction in anti-oxidants and creating defective and Amyloid proteins and integration of lipid pigments which change Hippocampus performance due to exudative destruction.
Considering a research by Rahmatabadi (2009), strong antioxidant compounds in Cinnamon bark can adjust destructive effects of oxidative stress. Thus, memory strengthening factor by cinnamon extract may be related to an antioxidant specification of cinnamaldehyde in the said extract. Another compound in the cinnamon extract is Proanthocyanin. Proanthocyanins are very active antioxidants (Akkarachiyasit, 2010). Proanthocyanin derived from cinnamon extract prohibits integration of Tau proteins in Alzheimer's disease (Petersona et al., 2009). Effects of Proanthocyanin derived from cinnamon extract were reviewed in terms of its prohibition from an integration of Tau proteins in vitro by Petersona et al. (2009). Tau proteins are separated by Anthocyanin compounds of cinnamon extract within a specified term, thus it is said that cinnamon extract can play a main role in hindering combination of beta-amyloidal plates which is considered a significant factor in Alzheimer's disease. Molecules of Poly-Phenol Polymeric are another derivations of Proanthocyanin which exist in the cinnamon extract (Vermerris \& Nicholson, 2006). Relevant Poly-Phenols can present information from Amyloid, independent of oxidation conditions, thus they can prevent neurotoxicity induced by beta-amyloid and assist symptoms of Alzheimer (Ranjbar et al., 2006). The capability of purifying free radicals is one of the significant specifications of anti-oxidation to minimize oxidation cells. The main and valid unstable compounds of cinnamon polyphenols such as Eugenol and methyleugenol in oil bark of cinnamon extract probably can decrease and destroy free radicals which are the origin of main neurological diseases such as Alzheimer (Sharma et al., 2015). Since no definite treatment is recognized as Alzheimer's disease and the present treatments can just prevent the progress of the disease and/or some treatment mayadjust some of its symptoms.

Results of our study show that injection of intracerebral ventricular STZ cause destructive effects on learning and memory in rats, although by injecting cinnamon extract to intraperitoneal, we can prevent destructive effects of STZ on learning and memory in rats.

\section{Acknowledgements:}

The authors are thankful to all such persons who helped them to construct this piece of work and paper in proper shape.

\section{References:}

Akkarachiyasit, S., Charoenlertkul, P., Yibchok-anun, S. \& Adisakwattana, S. (2010): Inhibitory Activities of Cyanidin and Its Glycosides and Synergistic Effect with Acarbose against Intestinal á-Glucosidase and Pancreatic á-Amylase. Int. J. Mol.Sci., 11(9):3387-3396.

Adsersen, A., Gauguin, B., Gudiksen, L. \& Jäger, A.K. (2005): Screening of plants used in Danish folk medicine to treat memory dysfunction for acetylcholinesterase inhibitory activity.JEthnopharmacol.104(3):418-422. 
Anderson, R.A., Broadhurst, C.L., Polansky, M.M., Schmidt, W.F., Khan, A., Flanagan, V.P., Schoene, N.W. \& Graves, D.J. (2004): Isolation and characterization of polyphenol type Apolymers from cinnamon with insulin-like biological activity. J. Agric. Food Chem., 52(1):65-70.

Assunção, M., Santos-Marques, M.J., Carvalho, F., Lukoyanov, N.V. \& Andrade, J.P. (2011): Chronic green tea consumption prevents age-related changes in rat hippocampal formation. Neurobiol. Aging.. 32(4):707-717.

Bush, A.I. (2001): Therapeutic targets in the biology of Alzheimer's disease. Curr. Opin. Psych., 14(4):341-348.

Duke, J., Bogenschutz-Godwin, M.J., duCellier, J. \& Duke, P.K. (1929): Handbook of medicinal herbs (2nd Ed.). Pub. By : CRC handbook of medicinal herbs.

Frydman-Marom, A., Levin, A., Farfara, D., Benromano, T., Scherzer-Attali, R., Peled, S., Vassar, R., Segal, D., Gazit , E., Frenkel, D. \& Ovadia, M (2011): Orally Administrated Cinnamon Extract Reduces â-Amyloid Oligomerization and Corrects Cognitive Impairment in Alzheimer's Disease Animal Models. Plos One., 6 (1): e16564.

Gasparini, L., Netzer, W.J., Greengard, P. \& Xu, H. (2002): Does insulin dysfunction play a role in Alzheimer's disease? Trends Pharmacol.Sci., 23(6):288-293.

Herring, A., Ambrée, O., Tomm, M., Habermann, H., Sachser, N., Paulus, W. \& Keyvani, K. (2008): Environmental enrichment enhances cellular plasticity in transgenic mice with Alzheimer-like pathology. Exp Neurol., 216(1):184-192.

Hoyer, S., Lee, S.K., Löffler, T. \& Schliebs, R. (200o): Inhibition of the neuronal insulin receptor. An in vivo model for sporadic Alzheimer disease? Ann. N. Y. Acad. Sci. 920:256-258.

Hoyer, S. \& Lannert, H. (2008): Long-term effects of corticosterone on behavior, oxidative and energy metabolism of parietotemporal cerebral cortex and hippocampus of rats: comparison to intracerebroventricular streptozotocin. J Neu. Transm. (Vienna).,115(9):1241-9124.

Ishrat, T., Hoda, M.N., Khan, M.B., Yousuf ,S., Ahmad, M., Khan, M.M., Ahmad, A., Islam, F. (2009): Amelioration of cognitive deficits and neurodegeneration by curcumin in rat model of sporadic dementia of Alzheimer's type (SDAT). Eur Neuropsychopharmacol., 19(9):636-647.

Ishrat, T., Khan, M.B., Hoda, M.N., Yousuf, S., Ahmad, M., Ansari, M.A., Ahmad, A.S., Islam, F. (2006): Coenzyme Q10 modulates cognitive impairment against intracerebroventricular injection of streptozotocin in rats. Behav. Brain Res., 171(1):9-16.

Kumar, A., Schapiro, M.B., Grady, C., Haxby, J.V., Wagner, E., Salerno, J.A., Friedland, R.P. \& Rapoport, S.I. (1991): Highresolution PET studies in Alzheimer's disease.
Neuropsychopharmacol., 4(1):35-46.

Lannert, H. \& Hoyer, S. (1998): Intracerebroventricular administration of streptozotocin causes long-term diminutions in learning and memory abilities and in cerebral energy metabolism in adult rats. Behav. Neurosci., 112:1199-208.

Lee, S.K., Hong, C.H., Huh, S.K., Kim, S.S., Oh, O.J., Min, H.Y., Park, K.K., Chung, W.Y., Hwang, J.K. (2002): Suppressive effect of natural sesquiterpenoids on inducible cyclooxygenase (COX-2) and nitric oxide synthase (iNOS) activity in mouse macrophage cells. L. Environ. Pathol. Toxicol. Oncol., 21(2):141-148.

Petersona, D.Y., Georgea, R.C., Scaramozzino, F., LaPointe, N.E., Anderson, R.A., Graves, D.J. \& Lew, J. (2009): Cinnamon extract inhibits tau aggregation associated with Alzheimer's disease in vitro. J. Alzheimers. Dis., 17(3):585-597.

Rahmatabadi, D.M.H., Vahidi M.A.R., Pilavaran, A.A. \& Farzan, F. (2009): Effect of cinnamon extract on formalin induced pain in rat. J. Shaheed Sadoughi Univ. Med. Sci., 17(2): 190-199. (Persian with abstract in English).

Ranjbar, A., Ghasmeinezhad, S., Zamani, H., Malekirad, A.A., Baiaty, A., Mohammadirad, A. \& Abdollahi, M. (2006): Antioxidative stress potential of Cinnamomum zeylanicum in humans: a comparative cross-sectional clinical study. Therapy., 3(1), 113-117.

Roussel, A.M., Hininger, I., Benaraba, R., Ziegenfuss, T.N., Anderson, R.A. (2009): Antioxidant effects of a cinnamon extract in people with impaired fasting glucose that are overweight or obese. L.Am. Coll. Nutr., 28(1):16-21.

Siegel, G.J., Agranoff, B.W., Albers, R.W., Fisher, S.K. \& Uhler, M.D. (1991): Basic Neurochemistry, Molecular, Cellular and Medical Aspects. (6th edition). Pub. By: Academic Press, Elsevier.

Sharma, V.K., Goyal, A. \& Sarma, S.G. (2015): Minocycline decreases acetylcholinestrase activity in intracereboventricular streptozotocin infused rats. Int. J. Pharma. Sci. Res., 1 (9): 52-57.

Vangalapati, M. Sree Satya, N., Surya Prakash, D.V. \& Avanigadda, S. (2012): A Review on Pharmacological Activities and Clinical effects of Cinnamon Species. Res. J. Pharma. Biol. Chem. Sci., 3(1) 653-363.

Vermerris, W. \& Nicholson, R. (2006): Phenolic Compound Biochemistry. Pub. By: Springer, Dordrecht, The Netherlands.

Wallenstein, M.C. (1991): Attenuation of epileptogenesis by nonsteroidal anti-inflammatory drugs in the rat. Neuropharmacology, 3o(6):657-663. 